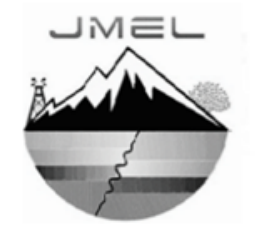

\title{
Kajian Kondisi Tutupan Karang Terhadap Daya Dukung Wisata Bahari Di Kepulauan Karimunjawa, Jawa Tengah
}

\author{
Johan Danu Prasetya ${ }^{1, \text { a) }}$, Dian Hudawan Santoso ${ }^{1)}$, Nabila Farhaini ${ }^{1)}$ \\ 1) Jurusan Teknik Lingkungan, Fakultas Teknologi Mineral, Universitas Pembangunan Nasional Veteran Yogyakarta \\ 1) a) Email korespondensi: johan.danu@ upnyk.ac.id
}

\begin{abstract}
ABSTRAK
Indonesia adalah satu negara yang mengandalkan pendapatan negara dari sektor pariwisata. Salah satu lokasi yang sekarang mulai banyak didatangi wisatawan lokal maupun wisatawan mancanegara adalah Kepulauan Karimunjawa. Kenaikan jumlah wisatawan di Karimunjawa akan berdampak terhadap kondisi terumbu karang. Penelitian ini bertujuan untuk mengetahui kondisi tutupan karang terhadap daya dukung wisata bahari di Perairan Kepulauan Karimunjawa. Data tutupan substrat diambil pada dua kedalaman yaitu dangkal (3-6 m) dan dalam (9-12 m), untuk masing-masing lokasi menggunakan metode Underwater Photo Transect (UPT). Data jumlah wisatawan baik snorkling maupun diving didapat dengan metode wawancara terhadap pelaku wisata di Karimunjawa, melalui Asosiasi Pemandu Wisata Karimunjawa. Hasil penelitian menunjukkan kondisi terumbu karang di Pulau Cemara Besar, Cemara Kecil, Menjangan Besar dan Menjangan Kecil, masuk dalam kategori sedang (25-49,5 \%) hingga baik (50-74,5 \%). Nilai daya dukung terbesar terdapat di Perairan Pulau Menjangan Kecil yaitu 194 orang untuk wisata snorkling dan 216 orang untuk wisata diving. Sedangkan nilai daya dukung terkecil ada di Perairan Pulau Cemara Kecil yaitu 36 orang untuk wisata snorkling dan 52 orang untuk wisata diving. Berdasarkan hasil yang didapat, dapat disimpulkan bahwa kondisi tutupan karang keras tetap berada pada kategori sedang-baik meskipun persentasenya ada yang mengalami penurunan maupun peningkatan. Jumlah wisatawan snorkling maupun diving yang berkunjung tidak melebihi kapasitas daya dukung lingkungan kecuali wisatawan snorkling di Perairan Cemara Kecil.
\end{abstract}

Kata Kunci: Daya dukung; karang keras; karimunjawa

\begin{abstract}
Indonesia is a country that relies on state revenues from the tourism sector. One location that is now popular among local and foreign tourists is the Karimunjawa Islands. The increase in the number of tourists in Karimunjawa will likely impact on the condition of coral reefs. This study aims to determine the condition of coral cover on the carrying capacity of marine tourism in the waters of the Karimunjawa Islands. Data consisting of substrate type and percent cover were taken at two depths i.e. shallow $(3-6 \mathrm{~m})$ and deep $(9-12 \mathrm{~m})$, for each location using the Under Water Photo Transect (UPT) method. The results showed that the condition of the four coral reefs in this study sites was in the moderate category $(25-49.5 \%)$ to good (50-74.5\%). Data on the number of tourists both snorkeling and diving was obtained by interviewing the relevant stakeholder. The highest average daily number of visitors is in the waters of Menjangan Kecil Island which is 194 snorkeling and 216 diving activity. While the lowest number of tourists is in the waters of Pulau Cemara Kecil, which is 88 tourists per day consisting of 36 snorkeling and 52 diving activity. Based on the results obtained, it can be concluded that the condition of hard coral cover remained in the medium-good category despite the decreasing or increasing coral cover percentage. The result also showed that the number of snorkeling and diving do not exceed the carrying capacity of the environment with the exception of snorkeling tourists in the waters of Cemara Kecil.
\end{abstract}

Keyword : Carrying capacity; cove; hard coral; karimunjawa

\section{PENDAHULUAN}

The World Tourism Organisation (WTO) melaporkan peningkatan aktivitas pariwisata di seluruh dunia, tiap tahun, dari 14,7\% pada tahun 1989 menjadi 21,9\% pada tahun 2000, atau \pm 25 juta orang pada tahun 1950 -an menjadi 443 juta pada 1990 (WTO, 1991). Hal ini akan berdampak pada peningkatan pendapatan negara. Indonesia adalah satu negara yang mengandalkan pendapatan negara dari sektor pariwisata. Salah satu lokasi yang sekarang mulai banyak didatangi wisatawan lokal maupun wisatawan mancanegara adalah Kepulauan Karimunjawa.

Secara administratif, Karimunjawa terletak di Kabupaten Jepara, Jawa Tengah, Indonesia. Terdapat 27 pulau di Kawasan Kepulauan Karimunjawa, namun hanya 22 pulau yang masuk pada Kawasan Taman Nasional. Secara geografis wilayah ini terletak pada koordinat 5 $5^{0} 40^{\prime} 39^{\prime \prime}-5^{0} 55^{\prime} 00^{\prime \prime}$ LS dan $110^{0} 05^{\prime} 57^{\prime \prime}-110^{0} 31$ '15" BT, dengan luas wilayah darat 7.033 ha 
dan luas wilayah laut 104.592 ha yang mencakup seluruh ekosistem hutan pantai, hutan dataran rendah, mangrove, lamun dan terumbu karang (Sumaryati et al., 2007). Taman Nasional Karimunjawa merupakan salah satu dari tujuh kawasan Marine Protected Area yang ada di Indonesia berdasarkan Surat Keputusan Menteri Kehutanan dan Perkebunan No. 78/Ktps-II/1999 tanggal 22 Februari 1999 (Campbell et al., 2013). Saat ini Taman Nasional Karimunjawa dikelola oleh Balai Taman Nasional Karimunjawa dalam rangka konservasi sumber daya alam hayati dan ekosistemnya. Taman Nasional Karimunjawa terbagi berdasarkan sistem zonasi, yang terdiri dari 9 zona. Pada wilayah perairannya terbagi menjadi beberapa zona, yaitu zona inti, zona perlindungan bahari, pemanfaatan bahari, zona budidaya bahari, dan zona perikanan tradisional. Kekayaan flora dan fauna yang ada di Karimunjawa terdiri dari 353 spesies ikan karang, 69 genus karang keras, 9 spesies lamun, 2 spesies penyu, 44 jenis mangrove (Kartawijaya et al., 2011).

Kepulauan Karimunjawa merupakan salah satu tujuan wisata bahari di Pantai Utara Jawa. Kegiatan pariwisata di Karimunjawa mempunyai peran penting terhadap ekonomi warga sekitar. Kunjungan wisatawan terus meningkat baik wisatawan lokal maupun wisatawan mancanegara. Pada tahun 1998 terdapat 450 wisatawan, jumlahnya meningkat hingga 20 kali lipat pada tahun 2005 menjadi 9000 wisatawan (Campbell et al., 2013), dan pada tahun 2019 menjadi 137.653 wisatawan (Disparbud Kab. Jepara, 2019). Hal tersebut berdampak terhadap ketersediaan lapangan kerja baru seperti menjadi pemandu wisata darat maupun laut, persewaan sepeda motor dan mobil, homestay, serta peningkatan permintaan produk makanan berbasis laut. Namun hal tersebut dapat berdampak terhadap ketersediaan stok ikan di laut apabila tidak ada pembatasan terhadap jumlah penangkapan.

Kenaikan jumlah wisatawan di Karimunjawa juga akan berdampak terhadap kondisi terumbu karang. Jumlah wisatawan harus dikelola agar tidak melebihi daya dukung wisata (Carrying capacity of tourism). Carrying capacity of tourism merupakan angka maksimum jumlah wisatawan yang dapat ditampung pada area destinasi wisata tertentu (O'Reilly, 1986). Konsep carrying capacity pada awalnya dikembangkan oleh Carey (1993) untuk melindungi satwa liar dengan gagasan dasar bahwa organisme dapat bertahan hidup hanya dalam kisaran kondisi fisik yang terbatas. Menurut penelitian Kartawijaya et al. (2010), terumbu karang di Kepulauan Karimunjawa mengalami kerusakan rata-rata $10 \%$ pertahun akibat adanya wisata bahari diving dan snorkling. Kerusakan yang dialami dapat berupa patahnya karang branching akibat terinjak wisatawan dan kerusakan akibat sampah plastik yang masuk ke laut dari kegiatan pariwisata. Berdasarkan hal tersebut, telah banyak dilakukan penelitian terhadap kondisi tutupan terumbu karang di Kepulauan Karimunjawa. Penelitian yang dilakukan Sulistyati et al., (2014) menunjukkan bahwa kondisi tutupan karang di Kepulauan Karimunjawa berada dalam kategori baik (50\% - 75\%) hingga sangat baik (>75\%). Penelitian Nadia et al. (2018) membandingkan kondisi tutupan karang di Pulau Bengkoang yang ditetapkan sebagai zona perlindungan bahari kondisi tutupan karang sebesar 80,31 \% dan zona pemanfaatan bahari untuk pariwisata sebesar 18,81\%. Selain itu Sabdono et al. (2019) juga menemukan 98 dari total 1686 koloni karang yang diamati di Kepulauan Karimunjawa mengalami Acroporid White Syndrome (AWS). Melihat pentingnya menjaga kondisi ekosistem terumbu karang demi keberlanjutan pariwisata bahari terutama snorkling dan diving, perlu dilakukan kajian daya dukung wisata yang ditentukan berdasarkan pertimbangan kondisi tutupan karang di Perairan Kepulauan Karimunjawa. Menurut Pearce (1989) daya dukung merupakan ambang batas kegiatan wisata yang tidak melampaui titik jenuh (daya dukung fisik), lingkungan terdegradasi (daya dukung lingkungan), atau kenikmatan pengunjung berkurang (persepsi atau daya dukung psikologis). Ketika jumlah pengunjung suatu kawasan wisata melebihi daya dukungnya, maka kerusakan lingkungan sulit untuk dihindari. Hal ini menyebabkan kepuasan terhadap tempat wisata tersebut mengalami penurunan.

Penelitian ini membandingkan data tutupan karang keras tahun 2019 dengan data yang diambil sebelumnya pada tahun 2014 (Sulisyati, et al., 2014) dan tahun 2016 (Prasetya, 2017). Penelitian ini bertujuan untuk mengetahui kondisi tutupan karang terhadap daya dukung wisata bahari di di Pulau Cemara Besar, Cemara Kecil, Menjangan Besar dan Menjangan Kecil, Taman Nasional Karimunjawa, Kabupaten Jepara, Provinsi Jawa Tengah.

\section{METODE}

Penelitian ini dilakukan di Kepulauan Karimunjawa, Jepara, Jawa Tengah yaitu pada pulau Cemara Besar (S: 05 ${ }^{\circ} 48^{\prime}$

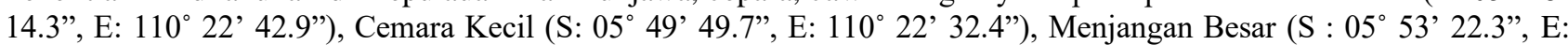
$\left.110^{\circ} 24^{\prime} 21.6^{\prime \prime}\right)$, dan Menjangan Kecil (S: 05 52' 42.5”, E: $110^{\circ} 24^{\prime}$ 58.5”) yang dijadikan Zona Pariwisata Bahari. Data tutupan substrat diambil pada dua kedalaman yaitu dangkal (3-6 m) dan dalam (9-12 m), pada bulan November 2019. Hasil persentase tutupan karang lalu dibandingkan data yang diambil sebelumnya pada tahun 2014 (Sulistya, 2014) dan tahun 2016 (Prasetya, 2017). Data primer diambil satu kali pada tiap kedalaman, menggunakan metode Underwater Photo Transect (UPT). Photo diambil setiap interval $0,5 \mathrm{~m}$ di atas transect garis sepanjang $50 \mathrm{~m}$. Pengambilan data dilakukan oleh dua orang penyelam dengan membawa transek kuadrat 50x50 cm dan salah satu penyelam bertugas mengambil gambar dengan jarak $\pm 60 \mathrm{~cm}$ tegak lurus terhadap objek. Hasil foto dianalisis menggunakan software CPCE dan dihitung struktur komunitasnya menggunakan rumus sebagai berikut (English et al., 1994): 


$$
n i=\frac{l i}{L} \times 100 \%
$$

ni : persen tutupan substrat

li : total panjang persubstrat

L $\quad$ : total panjang transek

Daya dukung ekosistem terumbu karang dihitung dengan rumus mengacu pada Sulisyati, (2016):

$$
C C=\frac{\% \text { HC } x \text { Vast Area of Coral Reef }}{\text { Vast Area of Activity }} x \text { Correction Factor }
$$

$\mathrm{CC}$

$$
\text { : Carrying capacity (ind) }
$$

$\mathrm{HC}$

$$
\text { : Hard Coral (\%) }
$$

Vast Area of Coral Reef : Luas total terumbu karang pada lokasi tersebut $\left(\mathrm{m}^{2}\right)$

Data jumlah wisatawan baik snorkling maupun diving didapat dengan metode wawancara terhadap pelaku wisata di Karimunjawa, melalui Asosiasi Pemandu Wisata Karimunjawa. Sedangkan data pendukung seperti Luas Area untuk Aktifitas, dan Faktor Koreksi mengacu pada penelitian Sulisyati (2016).

\section{HASIL DAN PEMBAHASAN}

\subsection{Persentase Tutupan Substrat}

Persentase tutupan karang keras pada masing-masing lokasi yang mewakili perairan dangkal yaitu 54,4 \% di Cemara Besar; 41,4 \% di Cemara Kecil; 51,03 \% di Menjangan Besar; dan 58,4 di Menjangan Kecil (Gambar 1).

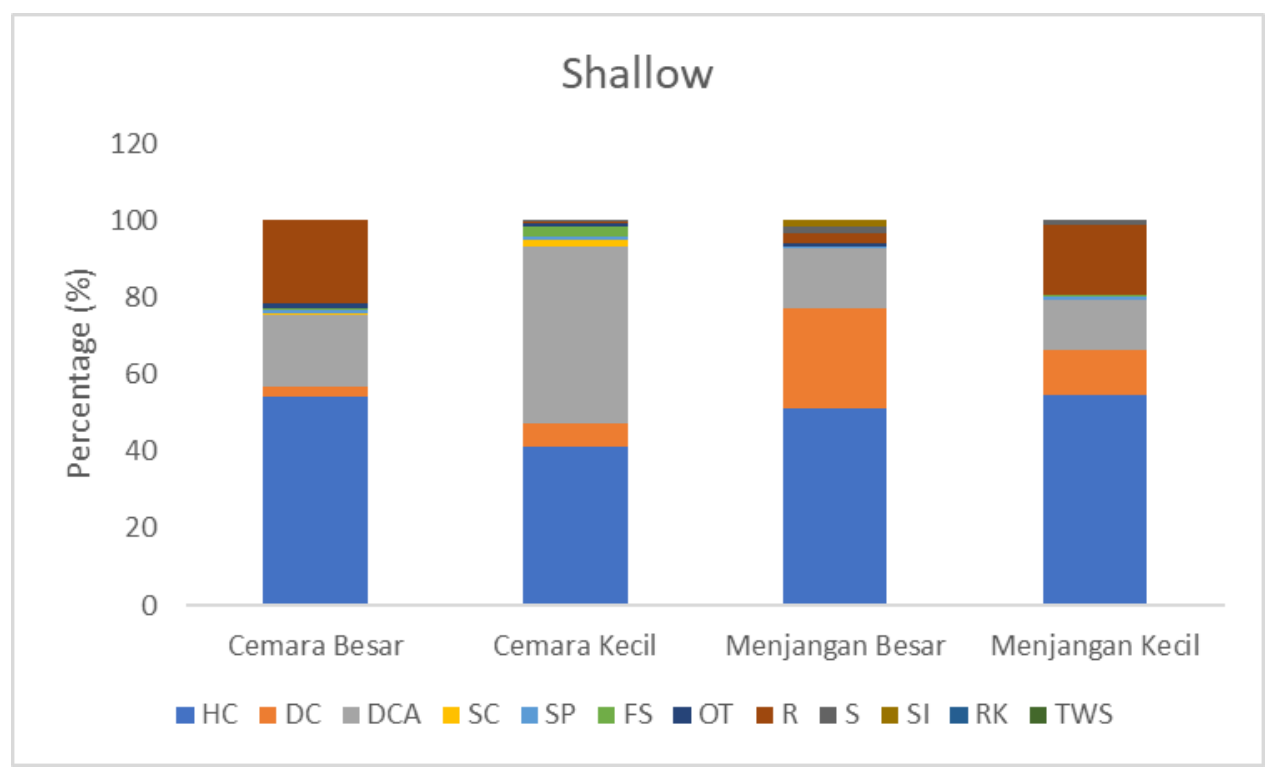

Gambar 1. Persentase Tutupan Substrat Dasar Perairan Dangkal.

Persentase tutupan karang keras pada masing-masing lokasi yang mewakili perairan dalam yaitu 43,55\% di Cemara Besar; 71,53 \% di Cemara Kecil; 35,35 \% di Menjangan Besar; dan 48,67\% di Menjangan Kecil (Gambar 2). 


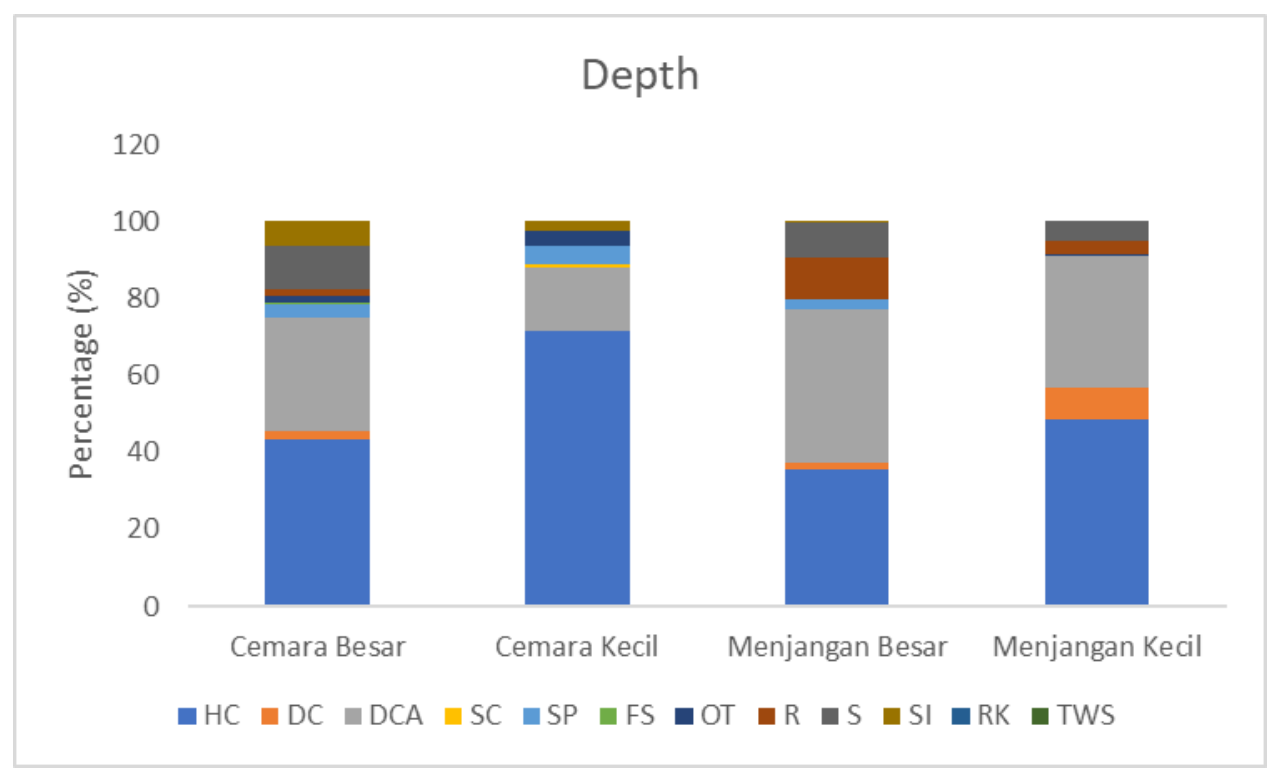

Gambar 2. Persentase Tutupan Substrat Dasar di Perairan Dalam.

Berdasarkan kriteria baku kerusakan terumbu karang Keputusan Menteri Negara Lingkungan Hidup No 4 tahun 2001, kondisi terumbu karang ke-empat lokasi penelitian masuk dalam kategori sedang $(25-49,5 \%)$ hingga baik $(50-74,5 \%)$.

\subsection{Perbandingan Persentase Tutupan Substrat dengan Tahun Sebelumnya}

Penelitian ini membandingkan data tutupan karang keras tahun 2019 dengan data yang diambil sebelumnya pada tahun 2014 (Sulisyati, et al., 2014) dan tahun 2016 (Prasetya, 2017) (Gambar 3). Dari perbandingan tersebut didapatkan hasil bahwa persentase tutupan karang keras mengalami peningkatan dari tahun 2014 ke tahun 2016, namun mengalami penurunan pada tahun 2019. Keempat lokasi yang diamati memiliki pola yang sama.

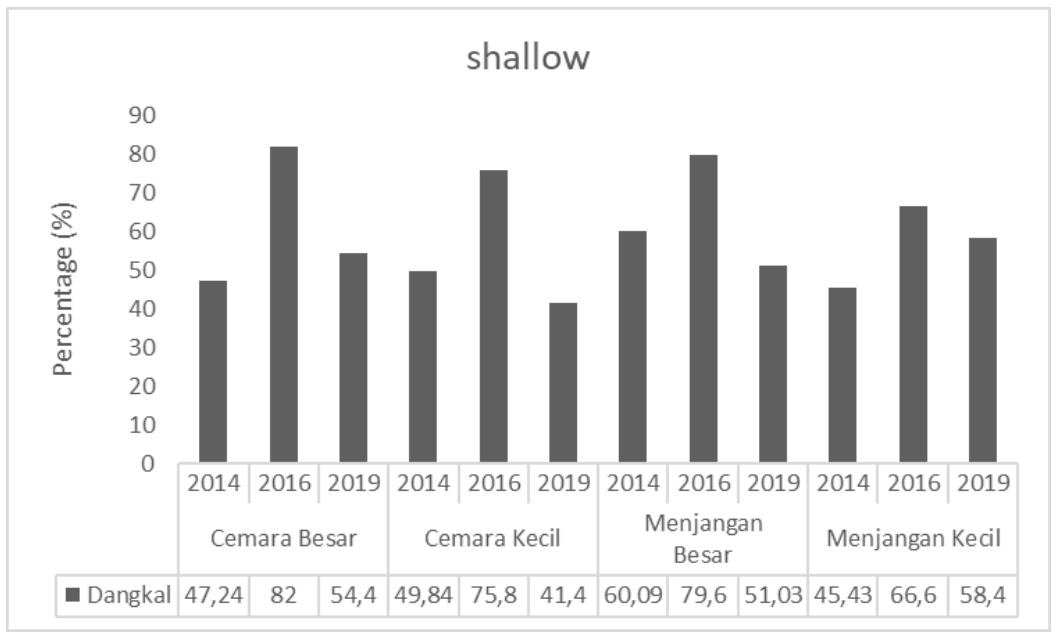

Gambar 3. Perbandingan Tutupan Karang Keras di Perairan Dangkal Tahun 2014 (Sulisyati, et al., 2014), 2016 (Prasetya, 2017) dan 2019.

Sama halnya dengan tutupan karang pada perairan dangkal, pada perairan lebih dalam (Gambar 4) juga cenderung mengalami hal yang sama yaitu tutupan karang keras tertinggi terdapat pada data yang diambil tahun 2016. Namun di Pulau Cemara Kecil, tutupan karang keras justru mengalami peningkatan dari tahun 2014 hingga tahun 2019. Bahkan tutupan karang keras di Perairan Pulau Cemara Kecil pada tahun 2019 juga merupakan tutupan tertinggi dibandingkan dengan lokasi lain yaitu sebesar 71,53 \%. Sedangkan tutupan karang keras terendah terjadi di Perairan Pulau Cemara Besar pada tahun 2014 yaitu sebesar 13,9\%. 


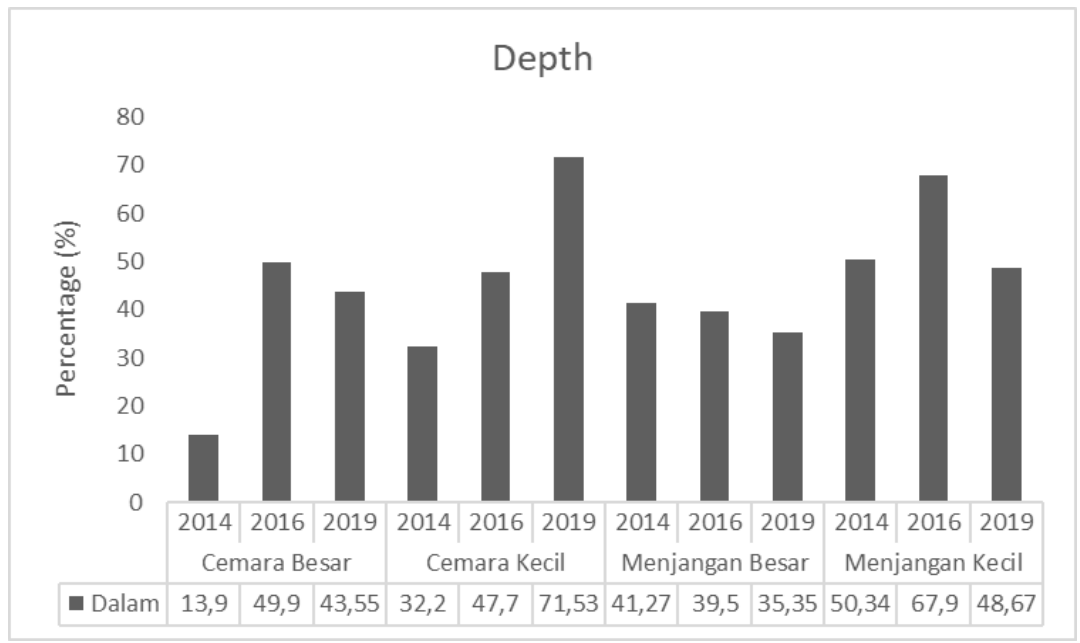

Gambar 4. Perbandingan Tutupan Karang Keras di Perairan Dalam Tahun 2014 (Sulisyati, et al., 2014), 2016 (Prasetya, 2017) dan 2019.

Kerusakan terumbu karang secara umum diakibatkan oleh faktor alam dan faktor manusia (Wijayanti et al., 2004). Faktor alam dapat berupa gelombang, sea level rise, dan ocean acidification. Sedangkan faktor manusia dapat berupa wisata bahari (Soebarjo dan Hidayat, 2007); penangkapan ikan menggunakan bom, bahan beracun, penambangan karang (Nadia et al., 2018); dan jangkar kapal (Haruddin et al., 2011). Kerusakan terumbu karang di Karimunjawa diduga lebih diakibatkan oleh faktor manusia.

Penelitian yang dilakukan oleh Sulisyati et al. (2014) pada zona pemanfaatan wisata di Karimunjawa juga menunjukkan hasil kondisi terumbu karang berada pada kategori sedang-baik. Hal ini menunjukkan tutupan terumbu karang di lokasi tersebut secara umum tetap berada dalam kategori kondisi sedang-baik, meskipun ada perubahan dalam persentase tutupannya.

\subsection{Daya Dukung}

Daya dukung tutupan karang keras di Zona Pemanfaatan Bahari dapat dilihat pada Tabel 1. Daya dukung tertinggi yaitu ada di Perairan Pulau Menjangan Kecil, yaitu dapat menampung hingga 410 wisatawan yang terdiri dari 194 wisatawan snorkling dan 216 wisatawan diving pemula. Kemudian untuk daya dukung terendah terdapat di Perairan Pulau Cemara Kecil yang hanya menampung 88 wisatawan yang terdiri dari 36 wisatawan snorkling dan 52 wisatawan diving.

Tabel 1. Daya Dukung Ekosistem Terumbu Karang Terhadap Kegiatan Pariwisata Bahari

\begin{tabular}{cccccccc}
\hline & & $\begin{array}{c}\text { Tutupan } \\
\text { Karang } \\
\text { Keras } \mathbf{\%})\end{array}$ & $\begin{array}{c}\text { Luas } \\
\text { Terumbu } \\
\text { Karang } \\
\mathbf{( H a )}\end{array}$ & Aktivitas & $\begin{array}{c}\text { Luas Area } \\
\text { untuk } \\
\text { Aktivitas } \\
\text { (Ha) }\end{array}$ & $\begin{array}{c}\text { Faktor } \\
\text { Koreksi }\end{array}$ & $\begin{array}{c}\text { Carrying } \\
\text { Capacity } \\
\text { (Ind) }\end{array}$ \\
\hline $\begin{array}{c}\text { Cemara } \\
\text { Besar }\end{array}$ & Dangkal & 54,40 & 134,65 & Snorkling & 0,20 & 0,50 & 183 \\
Cemara & Dalam & 43,55 & 134,65 & Diving & 0,20 & 0,42 & 123 \\
Kecil & Dangkal & 41,40 & 34,61 & Snorkling & 0,20 & 0,50 & 36 \\
$\begin{array}{c}\text { Menjangan } \\
\text { Besar }\end{array}$ & Dangkal & 71,53 & 34,61 & Diving & 0,20 & 0,42 & 52 \\
$\begin{array}{c}\text { Menjangan } \\
\text { Kecil }\end{array}$ & Dangkal & 51,03 & 187,71 & Snorkling & 0,20 & 0,50 & 239 \\
\hline
\end{tabular}


Data jumlah wisatawan untuk analisis daya dukung diperoleh dari hasil wawancara pada tahun 2019, terhadap 28 responden dari pelaku wisata di Karimunjawa, melalui Asosiasi Pemandu Wisata Karimunjawa, dapat dilihat pada Gambar 5. Jumlah responden sebanyak 28 orang telah mewakili keberadaan seluruh pemandu wisata yang ada di karimunjawa. Berdasarkan hasil analisis nilai daya dukung, nilai daya dukung terbesar terdapat di Perairan Pulau Menjangan Kecil yaitu 194 wisata snorkling dan 216 wisata diving. Sedangkan nilai daya dukung terkecil ada di Perairan Pulau Cemara Kecil yaitu 88 wisatawan per hari yang terdiri dari 36 wisata snorkling dan 52 wisata diving.

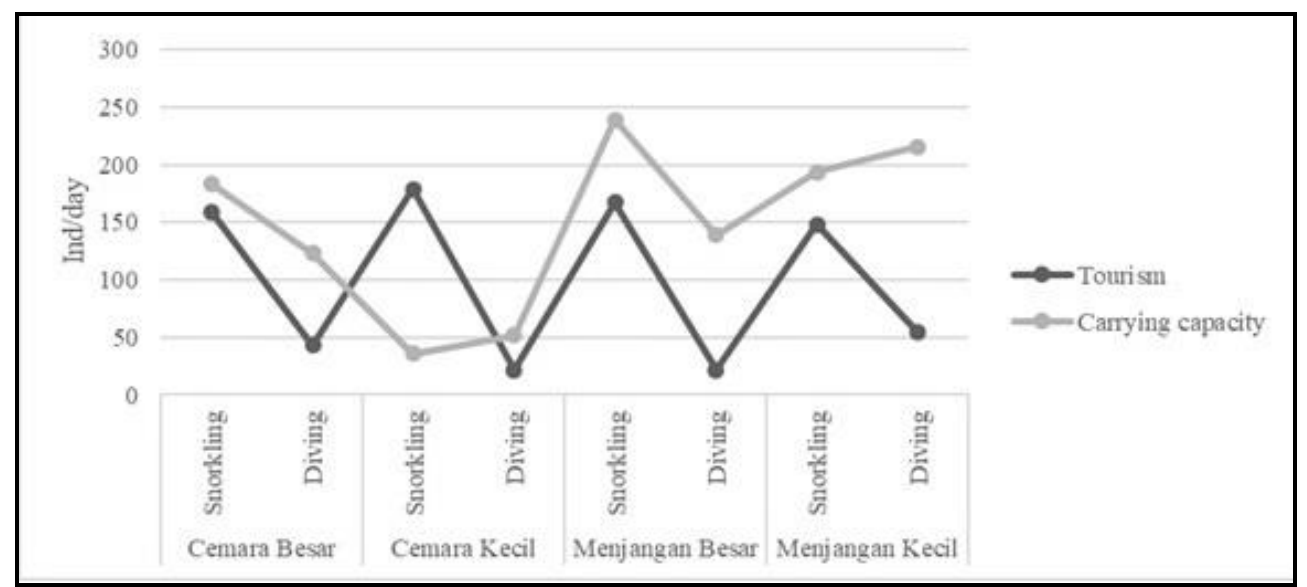

Gambar 5. Rata-rata jumlah wisatawan vs carrying capacity

Berdasarkan hasil wawancara tersebut dapat dilihat jika jumlah wisatawan per hari berada di bawah nilai daya dukung yang disarankan. Namun untuk kunjungan wisatawan snorkling di Perairan Pulau Cemara Kecil melebihi batas daya dukung yaitu 179 wisatawan snorkling per hari dengan nilai daya dukung hanya 36 wisatawan snorkling per hari. Jika dilihat dari Gambar 4 tutupan karang keras di Perairan Pulau Cemara Kecil mengalami penurunan dari tahun 2016 sebesar 75,8 \% menjadi 41,4\% pada tahun 2019. Hal ini dapat terjadi karena kelebihan kapasitas jumlah wisatawan. Beberapa wisatawan snorkling sangat berpotensi merusak terumbu karang di perairan dangkal dengan menginjak-injak maupun tidak sengaja menabrak terumbu karang dengan fins-nya, terutama karang bercabang yang sangat rentan patah. Karang bercabang banyak tumbuh di periaran dangkal yang dapat terjangkau oleh wisatawan saat mereka berdiri di kolom air.

Menurut Brown et al. (1997) terdapat beberapa masalah yang timbul dari pengembangan suatu kawasan wisata. Pertama adalah degradasi lingkungan yang menyertai peningkatan jumlah wisatawan. Hal tersebut dapat juga berasal dari masalah pembuangan limbah, serta ketersediaan dan kualitas air. Namun daya dukung merupakan hal yang dinamis (Zelenka and Kacetl, 2014). Pada kondisi yang berbeda, dampak wisata bahari terhadap lingkungan mungkin akan jauh berbeda maupun sebaliknya jika jumlah pengunjung sama. Sehingga pada beberapa lokasi yang berbeda butuh penanganan maupun kebijakan yang berbeda pula. Ada 3 komponen utama untuk melindungi ekosistem terumbu karang supaya tidak terjadi degradasi akibat dari pariwisata bahari yaitu manajemen lokasi oleh pejabat daerah terkait, pelaku pariwisata dan wisatawan itu sendiri (Zelenka, 2012).

\section{KESIMPULAN}

Berdasarkan hasil penelitian, dapat disimpulkan bahwa kondisi tutupan karang keras tetap berada pada kategori sedangbaik meskipun persentasenya ada yang mengalami penurunan maupun peningkatan. Jumlah wisatawan snorkling maupun diving yang berkunjung tidak melebihi kapasitas daya dukung lingkungan kecuali wisatawan snorkling di Perairan Cemara Kecil.

\section{UCAPAN TERIMA KASIH}

Penelitian ini dibiayai oleh Hibah Penelitian LPPM UPN "Veteran" Yogyakarta, dengan surat perjanjian Nomor B/286/UN.62/PT/X/2019. Terima kasih kepada Marine Diving Club (MDC) Ilmu Kelautan, Universitas Diponegoro yang merupakan bagian dari kegiatan penelitian. Terima kasih juga kepada Balai Taman Nasional Karimunjawa atas dukungan terhadap penelitian ini. 


\section{DAFTAR PUSTAKA}

Brown, K., R.K. Turner, H. Hameed, and I. Bateman. 1997. Tourism and Suistainability in Environmentally Fragile Areas Case Studies from the Maldives and Nepal. Environmental Conservation. DOI: $10.1017 / \mathrm{S} 0376892997000428$

Campbell, S.J., T. Kartawijaya, I. Yulianto, R. Prasetia, and J. Clifton. 2013. Co-management approaches and incentives improve management Effectiveness in the Karimunjawa National Park, Indonesia. Marine Policy. 41:72-79. http://dx.doi.org/10.1016/j.marpol.2012.12.022.

Carey, D.I. 1993. Development based on carrying capacity: A strategy for environmental protection. Global Environmental Change. 3(2): 140-148.

Dinas Pariwisata dan Kebudayaan Kabupaten Jepara. 2019. https://disparbud.jepara.go.id/wpcontent/uploads/sites/72/2020/01/Statistik-2019.pdf (diakses pada: 19 Desember 2020; 07.48 WIB)

Giyanto. 2013. Metode Transek Foto Bawah Air Untuk Penilaian Kondisi Terumbu Karang. Oseana 38 (1):47-61.

Haruddin, A., Purwanto, E., Budiastuti, M. S., \& Si, M. (2011). Dampak Kerusakan Ekosistem Terumbu Karang Terhadap Hasil Penangkapan Ikan Oleh Nelayan Secara Tradisional Di Pulau Siompu Kabupaten Buton Propinsi Sulawesi Tenggara. Jurnal EKOSAINS, 3(3), 29-41.

Kartawijaya, T., Prasetia, R., Ripanto, \& Jamaludin. 2011. Pengembangan Ekowisata Berbasis Masyarakat di Taman Nasional Karimunjawa. Bogor, Indonesia, 22 pp.: Wildlife Conservation Society - Indonesia Program.

Leujak, W. dan R.F.G. Ormond. 2007. Comparative accuracy and efficiency of six coral community survey methods. Journal of Experimental Marine Biology and Ecology. 351: 168-187. doi:10.1016/j.jembe.2007.06.028.

Nadia M., Nurhidayah, H. Alkharis, dan M. D. A. Malik. 2018. Differences of coral reef and coral community fish abundace condition based on zoning of Bengkoang Island, Karimunjawa. Jurnal Kelautan. Volume 11, No. 1. doi.org/10.21107/jk.v11i1.3709.

O’Reilly, A.M. 1986. Tourism Carrying capacity. Tourism Management. 7(4):254-258. DOI: 10.1016/02615177(86)90035-x.

Pearce, D.G. 1989. Tourist Development. Longman: Essex.

Prasetya, J.D. 2017. Penilaian kesehatan Ekosistem Pesisir di Kawasan Konservasi Laut: Studi Kasus Taman Nasional Karimunjawa Kabupaten Jepara Provinsi Jawa Tengah. Disertasi Program Doktor Manajemen Sumberdaya Pantai, Universitas Diponegoro, Semarang (tidak dipublikasikan).

Sabdono, A. O.K. Radjasa, and D.P. Wijayanti. 2019. Early Assessment of Shipping Route and Coral Cover as Drivers of Acroporid White Syndrome Outbreak in Karimunjawa, Java Sea, Indonesia. Environment Asia. 12(2) (2019) 126-135. DOI 10.14456/ea.2019.34.

Sulisyati, R. 2016. Daya Dukung Ekosistem Terumbu Karang untuk Kesesuaian Wisata Bahari di Taman Nasional Karimunjawa. Thesis. Program Studi Ilmu Kehutanan. Universitas Gajah Mada. Yogyakarta.

Sulisyati, R., E. Poedjirahajoe, L. Rahayu, and C. Fandeli. 2014. Karakteristik Terumbu Karang di Zona Pemanfaatan Wisata Taman Nasional Karimunjawa (Coral Reef Characteristic of Tourism Zone, Karimunjawa National Park). Indonesian Journal of Marine Science. Vol 19(3):139-148. DOI: 10.14710/ik.ijms.19.3.139-148.

Sumaryati, S., H. Susanto, Kuswadi \& M.S.J.E. Mardiko. 2007. Birds of Karimunjawa National Park. Balai Taman Nasional Karimunjawa, Semarang. (In Indonesian). 66: 1-9.

Susanto, H., I. Taufiqurrahman, and S. (Bas) V. Balen. 2014. Waders of Karimunjawa National Park, Central Java, Indonesia. The Journal for the East Asian-Australasian Flyway (Stilt). 66:1-9.

Wijayanti, D.P., C.A. Suryono, dan A. Sabdono. 2004. Pertumbuhan Karang Bercabang Acropora aspera, Stylophora pistilata, dan Pocillopora damicornis Hasil Planulasi di Laboratorium. Indonesian Journal of Marine Sciences. 9(2):86-89. DOI: doi.org/10.14710/ik.ijms.9.2.86-89.

World Tourism Organisation. 1991. Year Book of Tourism Statistics 1991. WTO. Madrid.

Zelenka, J. and J. Kacetl. 2014. The Concept of Carrying capacity in Tourism. Amfiteatru Economic. Vol. XVI. No 36.

Zelenka, J., 2012. Únosnákapacita v cestovnímruchu (Tourism Carring Capacity). Czech Journal of Tourism, 1(2), pp. 114-134. 